\title{
Atmospheric oxygenation driven by unsteady growth of the continental sedimentary reservoir
}

\author{
Jon M. Husson*, Shanan E. Peters* \\ Department of Geoscience, University of Wisconsin-Madison, 1215 W. Dayton Street, Madison WI, 53706, USA
}

\begin{abstract}
Atmospheric oxygen concentration has increased over Earth history, from 0 before 2.5 billion years ago to its present-day concentration of $21 \%$. The initial rise in $p \mathrm{O}_{2}$ approximately 2.3 billion years ago required oxygenic photosynthesis, but the evolution of this key metabolic pathway was not sufficient to propel atmospheric oxygen to modern levels, which were not sustained until approximately two billion years later. The protracted lag between the origin of oxygenic photosynthesis and abundant $\mathrm{O}_{2}$ in the surface environment has many implications for the evolution of animals, but the reasons for the delay remain unknown. Here we show that the history of sediment accumulation on continental crust covaries with the history of atmospheric oxygen concentration. A forward model based on the empirical record of net organic carbon burial and oxidative weathering of the crust predicts two significant rises in $p \mathrm{O}_{2}$ separated by three comparatively stable plateaus, a pattern that reproduces major biological transitions and proxy-based $p \mathrm{O}_{2}$ records. These results suggest that the two-phased oxygenation of Earth's surface environment, and the long delays between the origin of life, the evolution of metazoans, and their subsequent diversification during the Cambrian Explosion, were caused by step-wise shifts in the ability of the continents to accumulate and store sedimentary organic carbon. The geodynamic mechanisms that promote and inhibit sediment accumulation on continental crust have, therefore, exerted a first-order control on the evolution of Earth's life and environment.
\end{abstract}

Keywords: oxygen | Proterozoic-Phanerozoic transition | sedimentary record

*Corresponding author

Email address: husson@wisc.edu (Jon M. Husson)

Preprint submitted to Earth and Planetary Sciences

1. Introduction

The extraction and burning of organic carbon-based fossil fuels is reversing the processes of photosynthesis and sedimentation, thereby causing a rise in $\mathrm{CO}_{2}$ and concomitant $\mathrm{O}_{2}$ drop in Earth's atmosphere (Keeling and Piper, 1996). Although the global climate consequences of the former are cause for concern, the industrial-scale consumption of $\mathrm{O}_{2}$ is not considered a threat, despite the necessity of oxygen for animal life. The reason is because of the large quantity of free $\mathrm{O}_{2}$ in the surface environment, a product of organic

(C) 2016. This manuscript version is made available under the Elsevier user license http://www.elsevier.com/open-access/userlicense/1.0/ 
carbon burial and sequestration in sediments. With respect to the history of atmospheric oxygen, this discrepancy highlights a critically important fact: biological photosynthesis is a necessary condition for the rise of atmospheric oxygen, but it is insufficient to produce an $\mathrm{O}_{2}$-rich atmosphere unless it is coupled to the sequestration of organic carbon in sedimentary deposits (Hayes and Waldbauer, 2006).

The recognition that Earth's surface chemistry is controlled, at the most fundamental level, by mass exchanges between the surface environment and the lithosphere has been recognized for over 100 years (Chamberlin, 1899). However, because data with which to constrain global mass fluxes into and out of the sedimentary reservoir are difficult to assemble, proxy records are used typically to interrogate the evolution of Earth's surface environment. For example, measurements of mass-independent fractionation (MIF) of sulfur isotopes (Farquhar et al., 2000) define an initial rise in atmospheric oxygen by $\sim 2300$ million years ago (Ma) - an event referred to as the 'Great Oxidation Event' ('GOE', Holland, 1999). Measuring levels of atmospheric oxygen from the GOE to its present concentration of $21 \%$ is notoriously difficult. Nevertheless, a proxy-based history has emerged in which $p \mathrm{O}_{2}$ was stable but low throughout the Proterozoic $(\sim 2300-$ $\sim 635$ Ma), with an anoxic deep ocean (Reinhard et al., 2013; Scott et al., 2008). This long-term plateau ended in the terminal Proterozoic (Sahoo et al., 2012), with a rise that may have been gradual (Bergman et al., 2004; Sperling et al., 2015) or sudden (Berner and Canfield, 1989), but that achieved modern levels by the early Paleozoic ( $\sim 400 \mathrm{Ma})$. Ideas about $p \mathrm{O}_{2}$ variability within the Phanerozoic (Fig. 1) are informed primarily by numerical models coupled to proxy constraints (Berner, 2005; Bergman et al., 2004).

A 'three phase' hypothesis for atmospheric oxygen levels (Fig. 1) is emerging as a fundamental feature of Earth history, albeit one that continues to be tested and challenged (Lyons et al., 2014). The potential mechanisms driving this history, however, are less well known. An $\mathrm{O}_{2}$-free Archean has been explained by more reducing volcanism (Holland, 1984) or an absent biological $\mathrm{O}_{2}$ source (Kirschvink and Kopp, 2008), but the long-term maintenance of an intermediate Proterozoic plateau in atmospheric $p \mathrm{O}_{2}$ (Fig. 1) is difficult to explain. Carbon isotopic measurements of Proterozoic marine carbonates (Bartley and Kah, 2004; Knoll et al., 1986; Halverson et al., 2005) imply sustained organic carbon burial rates that were $\sim 1-2 \times$ Phanerozoic levels, assuming exogenic carbon mass fluxes and their isotopic compositions were approximately equivalent (Hayes and Waldbauer, 2006). Such high net $\mathrm{O}_{2}$ production rates are potentially incongruent with low $p \mathrm{O}_{2}$ in the Proterozoic (Johnston et al., 2009; Schrag et al., 2013; Laakso and Schrag, 2014; Derry, 2015).

Earth's sedimentary shell contains $1.25 \times 10^{21}$ moles of organic carbon (Berner and Canfield, 1989), equivalent to $\sim 33$ modern atmospheres of oxygen. Despite representing a large, net source of $\mathrm{O}_{2}$, the integrated history of deposition and erosion on the continents that has yielded this mass of organic carbon remains unknown. Although some organic carbon burial does occur on oceanic crust $(<10 \%$ today, Hedges and Keil, 1995), recycling of most or all of this sediment can occur as this crust is consumed at convergent margins, with a seafloor half-life of $\sim 62.4 \mathrm{Myr}$ in the modern (Rowley, 2002). A recent survey suggests that little carbon is returned to the convecting mantle via downgoing slabs, either migrating into the overlying mantle and crustal lithosphere or volatizing through arc volcanoes and diffuse outgassing (Kelemen and 


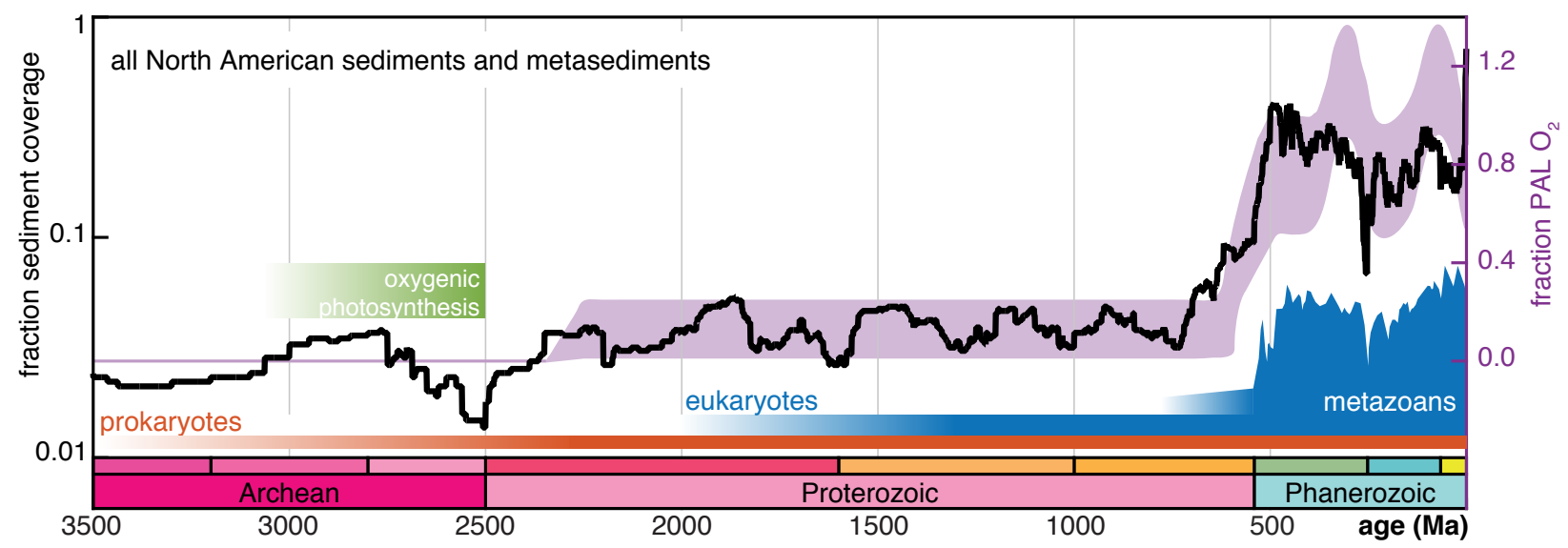

Figure 1: Empirical sedimentary and metasedimentary coverage in North America (left logarithmic y-axis, measured as proportion of geologic columns containing any sediment of a given age) is displayed along with the canonical history of atmospheric oxygen (right linear y-axis, Lyons et al., 2014). A schematic depiction of major biological events in the Earth system is depicted also, including the origins of oxygenic photosynthesizers (Lyons et al., 2014), eukaryotes (Lyons et al., 2014) and metazoans (Erwin et al., 2011), and scaled biodiversity of Phanerozoic marine animals (Hannisdal and Peters, 2011).

Manning, 2015). The fate of the reducing power of subducted sediments is a related but more complex question. It has, however, been suggested that most or all of the reducing power of deep sea sediments is returned to the surface environment during seafloor destruction, at least presently (Hayes and Waldbauer, 2006). If correct, while carbon storage on ocean crust is significant compared to the residence time of atmospheric $\mathrm{O}_{2}$ (millions of years, Hedges and Keil, 1995), the most important determinant of atmospheric $\mathrm{O}_{2}$ on billion year timescales is the net accumulation of organic carbon in continental sedimentary deposits a conceptual approach that has been widely applied (e.g., Berner and Canfield, 1989; Hayes and Waldbauer, 2006; Lee et al., 2016). Here we consider explicitly the connection between the net growth of Earth's continental carbon reservoir and atmospheric oxygenation. We do this by first measuring net sedimentary burial in continental settings and by then using this history to constrain a simple forward model for $p \mathrm{O}_{2}$.

\section{Methods}

\subsection{Macrostrat database}

Macrostrat (https://macrostrat.org) is a relational geospatial database that describes the chronological age and spatial distribution of rocks and sediments in the upper crust. Data here derive from the North American component, characterized by 23,813 lithostratigraphic units contained within 949 geographic columns (Fig. S1). Units in Macrostrat are assigned a variety of physical attributes, including thicknesses, dominant and subordinate lithologies, attributes that modify lithologies (e.g. 'black shale,' 'stromatolitic limestone'), lithostratigraphic nomenclature and age estimates. All Macrostrat units have at least one dominant lithology, but multiple lithologies, and the relative proportional abundances of each, can be recorded. 

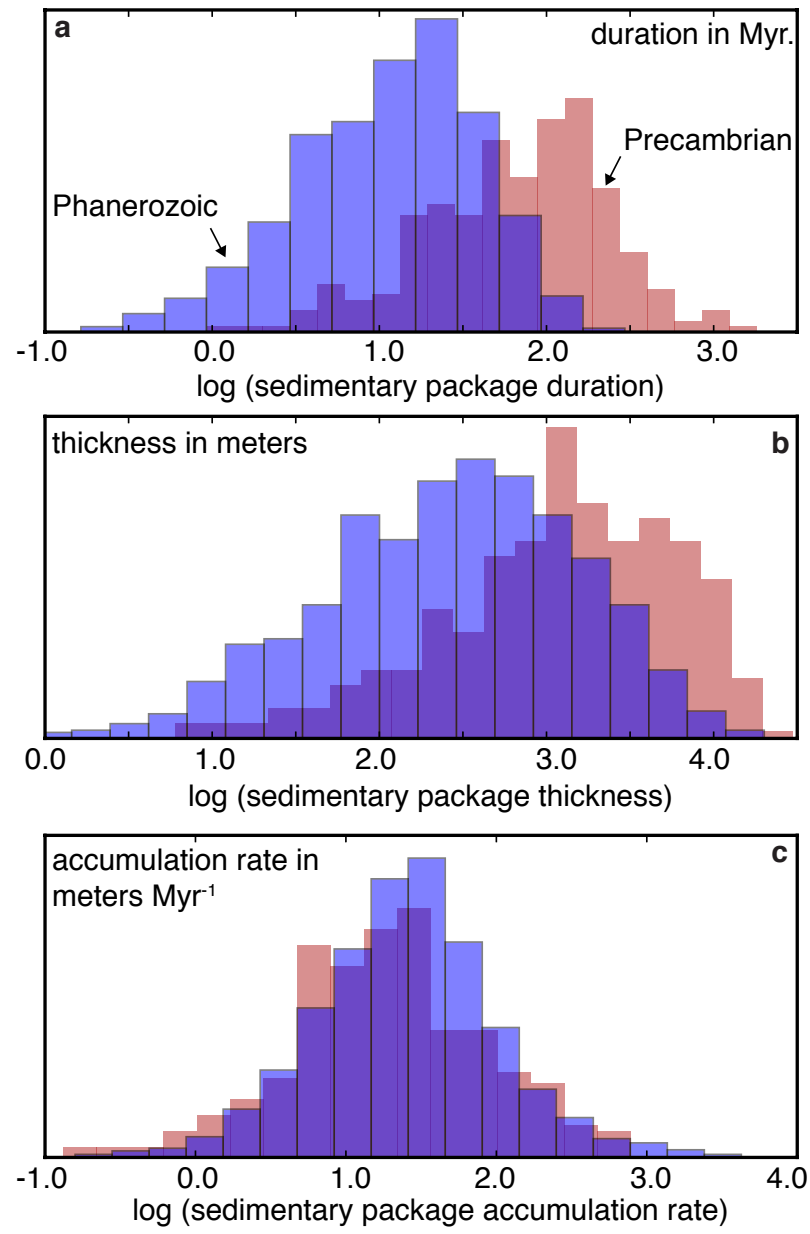

Figure 2: Distribution of durations (a), thicknesses (b) and accumulation rates (c) for Precambrian and Phanerozoic sedimentary packages (i.e., an interval of sediment accumulation bound by hiatuses) as defined by Macrostrat's age model.

Each unit acquires a modeled numerical age by using basic correlations to chronostratigraphic intervals and the contact relationships among units in the same column. For example, if there are 5 vertically stacked sedimentary units bounded by hiatuses in a column, and if together those units spanned one chronostratigraphic time bin (e.g., the Frasnian), then the time represented by the chronostratigraphic bin would be distributed, in a relative sense, equally and sequentially between each successive unit.

Parsing time in the sedimentary rock record is more difficult in the Precambrian as compared to the Phanerozoic, owing to the absence of widespread index fossils in the former. Thus, even in the absence of direct radiometric dating of a stratigraphic succession, biostratigraphic arguments potentially allow for the construction of a basic age model for many Phanerozoic sediments. The lack of a biological chronostratigraphic tool may explain the observed longer mean duration of Precambrian 'sedimentary packages' defined here as an interval of sedimentation bound by hiatuses of at least 1 Myr duration (Peters, 2006). Consistent recognition of Precambrian hiatuses may be more challenging without chronostratigraphic biozones, thereby leading to longer-duration sedimentary packages (Fig. 2a). However, Precambrian packages 
are also, on average, thicker (Fig. 2b). Thus, the distributions of Precambrian and Phanerozoic rates of sediment accumulation are quite similar (Fig. 2c).

Data to create Fig. 1 are available via the Macrostrat application program interface (API) at:

The number of columns that have sediments or metasediments are tabulated for each one million year increment, with the minimum possible value being 0 and the maximum 949 (if all regions are occupied by sediment of that age). The sediment coverage record (Fig. 1) is then built by normalizing the time series to the maximum value (i.e., a value of 1 would indicate all of Laurentia is accumulating sediment at a given time point). For flux calculations, the volume of each rock unit is distributed linearly between its bottom and top age. The Macrostrat API output is produced dynamically from the current information in the database. The specific data used here, as well as the summarized sediment coverage record, are archived in Dataset S1.

\subsection{Modeling global sediment volumes}

One challenge in using Macrostrat as a basis for exploring global sedimentary processes is that, at present, it only covers $\sim 16 \%$ of continental land area (Fig. S1). A model must, therefore, be used to scale Macrostrat sediment volumes to global values. Here, we base this model on a comparison to the work of Alexander Ronov (Ronov et al., 1980; Ronov, 1982), who generated globally comprehensive rock volume estimates for general lithologies and epochs (or longer duration time intervals) in the Phanerozoic and latest Precambrian. Sediment fluxes from this compilation are shown in Fig. 3a, derived by normalizing sediment volumes by bin duration. A Macrostrat-based sediment volume flux model can be produced at the same time resolution as Ronov's, using rock unit thicknesses, areal extents and age estimates (Fig. S1). This time series can become an initial global model (blue in Fig. 3a) by multiplying the ratio of global continental area captured by Ronov's synthesis to Macrostrat's areal coverage ( 6.07).

As is the case for any proxy dataset, Ronov's sediment volume compilation is not perfect and has its limitations. Of these, the most relevant for this work are the coarse temporal resolution at which data were compiled ( 15 Myr bin durations or greater) and the difficulty in editing binned sediment volume estimates as correlations, age models and timescales are updated and improved. However, it remains the only compilation of global sediment volume for the Phanerozoic and latest Proterozoic, and was constructed independently of Macrostrat. Thus, the two syntheses can be compared, with commonalities between them constituting meaningful evidence that each are useful models of extant sediment volumes.

Both datasets yield congruent time series of global sediment volume (partial correlation on first-differences with changes in interval duration held constant: Spearman's $\rho=0.50, \mathrm{P}=0.02$; Pearson product-moment $\mathrm{r}=0.79, \mathrm{P}=0.00002$ ). The total amount of Phanerozoic sediment in Ronov's synthesis is 639 million $\mathrm{km}^{3}$; the simple area-based scaling of Macrostrat's Phanerozoic estimate $(\times 6.07)$ is within $3 \%$ of this value $(620$ million $\mathrm{km}^{3}$ ). By comparison, the scaled estimate for Macrostrat's Precambrian sediment volume is 222 

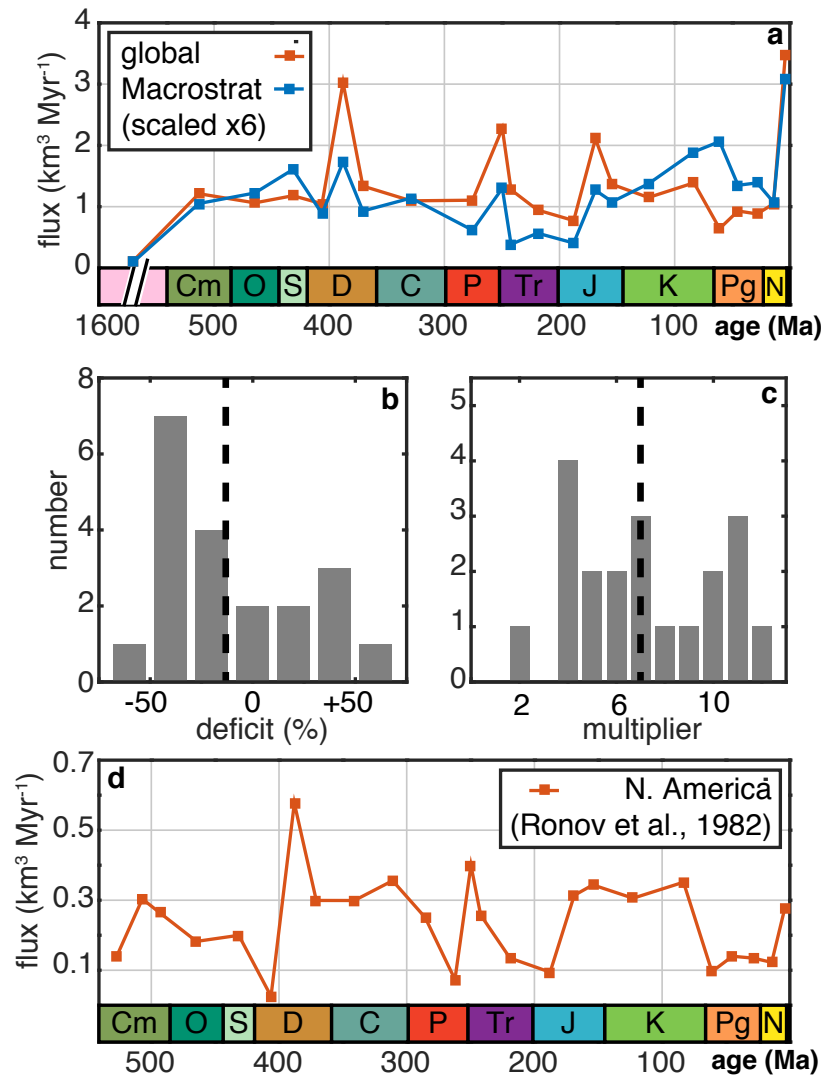

Figure 3: (a) Time series of global (red curve, Ronov et al., 1980) and Macrostrat sediment volume fluxes (blue curve, scaled by a constant factor of 6.07 to become a global estimate) are displayed. (b) Comparison of the red and blue curves in (a) can be expressed as a distribution of misfits between the models, defined as (Macrostrat / global) - 1 and expressed as percent deficit - note that the Paleocene $(+221 \%)$ is not shown. (c) Distribution of multiplicative factors needed to bring Macrostrat's global model into agreement with Ronov's estimate - note that the Middle Triassic (20.1x) is not shown. Dashed lines in $\mathbf{b}$ and $\mathbf{c}$ are median values for each distribution. (d) Ronov's estimate for sediment flux for North America alone (Ronov, 1982).

million $\mathrm{km}^{3}$, an amount equivalent to approximately one third of the Phanerozoic total, despite representing $\sim 6 \times$ more elapsed geologic time.

If North American volumes are removed from Ronov's global time series, the correlation between Macrostrat and Ronov persists ( $\rho=0.47, \mathrm{P}=0.04 ; \mathrm{r}=0.64, \mathrm{P}=0.003)$. This finding is consistent with Ronov's conclusion that global processes predominate over local processes in governing changes in sediment quantity (Ronov et al., 1980). The distribution of residuals between the initial Macrostrat and Ronov models are shown in Fig. 3b; for example, the scaled Macrostrat model predicts $2.2 \times$ more sediment in the Paleocene as seen in Ronov's compilation. The scale factors needed to bring Macrostrat's global sediment volume estimate into strict agreement with Ronov's are shown in Fig. 3c. Although few in number, the scaling factors are distributed around the initial scaling (6.07), with the Middle Triassic being the only outlier.

The scale factors (Dataset S1) used to generate the Phanerozoic global sediment volume flux model are presented in Fig. 4. The only exception is the Middle Devonian; the scale factor needed to yield agreement 
is 10.6, but the initial model is used. This adjustment is justified by an examination of Ronov's compilation, parsed by region (Fig. 3d). In North America, the Middle Devonian is predicted to have the highest flux in the entire Phanerozoic, while the Early Devonian is predicted to have the lowest. We find this scenario unlikely, and believe it indicates correlation issues in Ronov's original compilation, wherein what is now considered Early Devonian strata was then placed in the Middle Devonian. This difference in correlation, along with a subsequent redefinition of the Early-Middle Devonian boundary, affected Ronov's Middle and Early Devonian volumes. This particular change, however, has no effect on the most important implication of these results - the dramatic increase in continental sediment accumulation seen across the ProterozoicPhanerozoic boundary (Fig. 1).

Lastly, Ronov (Ronov et al., 1980) does include a Precambrian estimate, but its bin duration is too coarse ( 1000 Myr), and correlations are too uncertain to justify strict usage. Thus, in each model instance, a scale factor for each Precambrian period bin is sampled with replacement from the observed distribution of Phanerozoic factors (Fig. 3c). The global sedimentation model is run 1000 times, with the shaded red region in Fig. 4a covering $95 \%$ of the Precambrian model outputs.

\section{Results}

\subsection{Continental sedimentation history}

Sedimentary and metasedimentary rock coverage, a presence-absence measure of rock quantity compiled from 949 regions in the North American component of the Macrostrat database (Methods, Fig. S1), is low in the Archean, rises to a higher value in the Proterozoic, and then again rises dramatically during the early Phanerozoic (Fig. 1). Previous analysis of the Phanerozoic portion of this record identified quantitative signals of global tectonics, notably the supercontinental coalescence and breakup cycle (Meyers and Peters, 2011). The presence of modes in sedimentation within the Proterozoic that are similarly spaced by $\sim 400$ Myr (Fig. 1) suggests that a supercontinent-like tectonic cycle may have exerted a first-order control on continental sediment accumulation within the Proterozoic as well.

The prevalence of a global tectonic signal within the Phanerozoic (Meyers and Peters, 2011), and possibly within the Proterozoic (Fig. 1), does not help to explain the dramatic increase in sediment quantity that is observed during the Proterozoic-Phanerozoic transition. Intrinsic measurements of sedimentary systems (i.e., estimated accumulation rates) show no change across this boundary (Fig. 2), thus indicating that the implied increase in sediment accumulation is not an artifact of the Macrostrat database and its ability to estimate Precambrian vs. Phanerozoic stratigraphic properties. Instead, this boundary marks a major stepwise increase in the extent of continental flooding that coincided with, and perhaps resulted in, a step-wise increase in the accumulation of sediments on the continents (Peters and Gaines, 2012). It is notable that exponential decay in surviving rock quantity with increasing age, as expected by models of rock cycling (Gregor, 1968; Garrels and Mackenzie, 1969; Gregor, 1970; Wold and Hay, 1990), is not apparent in the empirical rock quantity-age data (Fig. 1). Variation in original rates of erosion and/or deposition could 
result in higher frequency rises and falls in surviving sedimentary rock quantity, but if erosion were the dominant process, then these fluctuations would still be superimposed on an approximately exponential decrease in surviving sediment quantity with increasing age (Garrels and Mackenzie, 1971b,a; Mackenzie and Pigott, 1981).

The lack of the expected, approximately exponential decrease in sediment quantity was also noted by Alexander Ronov (Ronov et al., 1980), whose global sediment volume compilation for the Phanerozoic and latest Proterozoic produces a very similar trajectory to that documented in Fig. 1 (see Fig. 3). Ronov concluded from this observation that the main factor driving the observed fluctuations in sediment abundance on the continents must reflect primarily variation in net sediment accumulation, not subsequent modification of sediments by erosion (Ronov et al., 1980). Importantly, the observed sediment quantity-age data suggest that the global sediment mass stored on the continents has not remained constant, but has instead undergone episodes of net growth. Although we do consider the implication of an erosion-dominant process interpretation of Fig. 1, this scenario requires contrived, time-varying rates of sedimentation and erosion (see section 4).

Given that variation in the sedimentary record is a proxy for changes in net sedimentation on the continents, an important next step is scaling our Macrostrat-derived record (Fig. 1) to arrive at a global model (Methods). Previous work has argued for global relevance of the Phanerozoic portion of the dataset by documenting a strong correlation with independent global biological, geochemical, and eustatic sea level records (Meyers and Peters, 2011; Hannisdal and Peters, 2011). Analogously, the overall time series of North American continental sediment abundance is strikingly similar to the global history of atmospheric oxygen concentration and major transitions in the global fossil record (Fig. 1). This covariation, alone, is notable and suggests that there is a process connection. Comparisons between the Macrostrat data (Fig. 1), Ronov's global rock volume data (Ronov et al., 1980), global geological maps, and Australian stratigraphic nomenclature data further indicate that North America is a sufficiently large sample of the continental crust ( $\sim 16 \%$ of present-day continental area), to be globally representative (see supplementary online material section S1 and Figs. 3, S2 and S3).

\subsection{Organic carbon accumulation on continental crust}

To estimate net global continental sediment accumulation across Earth history, we scale Macrostrat's sediment volume flux (blue curve in Fig. 4a, Methods) upward to become a global model (red curve in Fig. 4a) using Ronov's global Phanerozoic and late Proterozoic compilation (Ronov et al., 1980, Methods and Fig. 3). To estimate the total organic carbon (TOC) content of this sediment, we used 49,803 sedimentary lithological characterizations in Macrostrat supplemented with 5,466 weight percent TOC measurements from the USGS National Geochemical Database (USGS, 2008) (supplementary online material section S2, Fig. S4). The time varying lithological properties of North American sediment (e.g., temporal shifts in the abundance of coal) translates into a changing expectation for the average sediment TOC content over time (Fig. 4b). The organic carbon burial flux in North America (blue line in Fig. 4c) is estimated from both its 

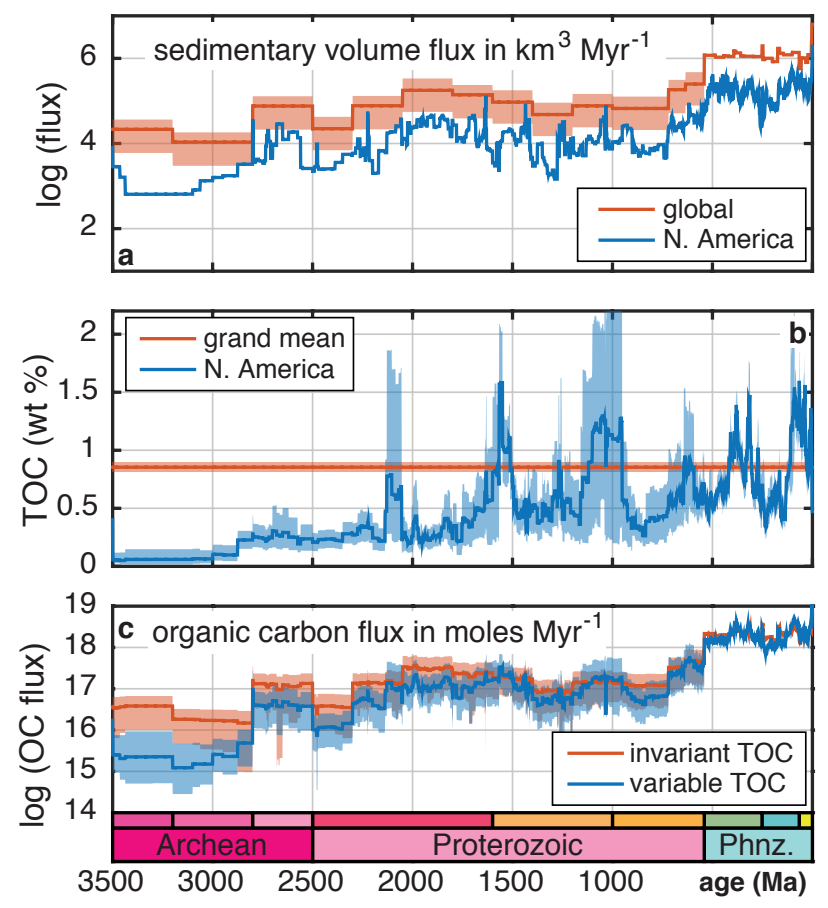

Figure 4: (a) Continental sediment flux models are shown for North America (blue curve) and the globe (red curve). (b) Using Macrostrat's lithological descriptions (supplementary online material section S2), the TOC content of bulk sediment in North America is predicted. (c) By combining (a) with (b), two endmember global organic carbon burial models are produced (red and blue curves). Shaded regions in (a-c) cover $95 \%$ of values produced by random assignment of properties defining sediment and organic carbon fluxes (supplementary online material section S2).

sedimentary volume flux (blue line in Fig. 4a) and its lithology-dependent TOC estimate (blue line in Fig. $4 b)$.

Given the empirical record of North America (Fig. 1), there are two approaches to characterizing the TOC content of the global continental sedimentary reservoir (Fig. 4): either TOC of sediment outside of North America mirrors the temporal variability expressed in the North American record (blue line in Fig. $4 \mathrm{~b}$ ), or the TOC content of the remaining global flux is invariant and equal to bulk average sedimentary composition (red line in Fig. 4b). When integrated, the 'variable TOC' model (blue line in Fig. 4c) predicts that the total amount of organic carbon in Earth's continental sedimentary shell is between 1.0 to $2.0 \times$ $10^{21}$ moles, with a median prediction of $1.37 \times 10^{21}$ moles. This estimate for the global mass of organic carbon in sedimentary deposits is within $10 \%$ of other independent global estimates (Berner and Canfield, 1989). The median prediction of the 'invariant TOC' model (red line in Fig. 4c) predicts a slightly higher total integrated value $\left(1.6 \times 10^{21}\right.$ moles $)$.

An important consideration when combining net continental sediment flux (Fig. 4a) with lithologyspecific TOC estimates (Fig. 4b) in order to estimate net organic carbon burial over time (Fig. 4c) is whether the TOC content of Precambrian sediments differ systematically from those of the Phanerozoic. We test this possibility for shale lithologies, using 3,346 TOC measurements from the USGS database (USGS, 2008), as 


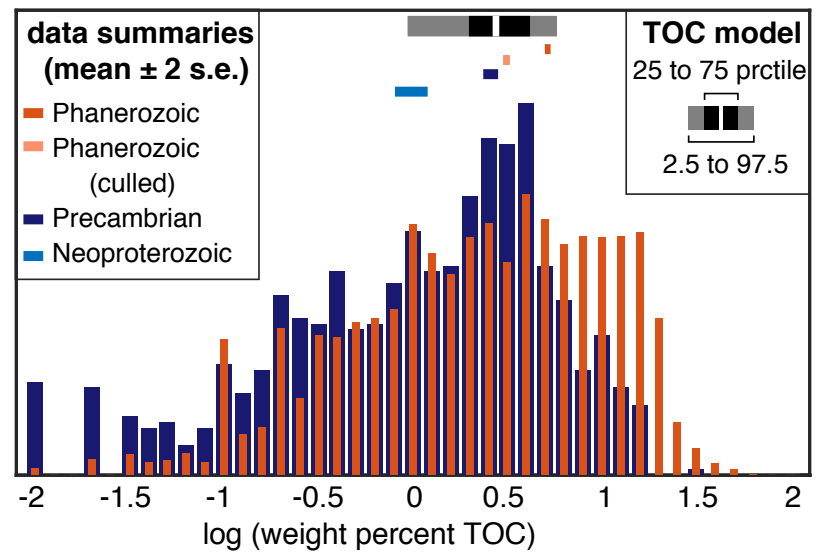

Figure 5: Normalized Precambrian and Phanerozoic distributions of shale weight percent TOC measurements from the USGS National Geochemical Database $(\mathrm{n}=3,346$, USGS, 2008) and from $(\mathrm{n}=2,398$, Partin et al., 2013). Data summaries (mean \pm 2 standard errors) are included at the top for comparison, along with quantiles of the distribution of modeled, formation-scale TOC values for shales (grey, black and white bar). The model values shown are only for shale bodies not described as 'red' (see supplementary online material section S2).

well as 2,398 measurements from Partin et al. (2013). These data are combined, and the distributions of Precambrian and Phanerozoic TOC values are plotted together in Fig. 5. The two distributions are similar, diverging most strongly only at high TOC values ( $>10$ weight percent). If the stratigraphic units with TOC values $>20 \%$, which are known to be unusual, are culled from the data, then the Phanerozoic mean is very close to the Precambrian mean (dark blue and lighter red horizontal bars in Fig. 5). In either case, there is little difference between Precambrian and Phanerozoic shale TOC content, at least among shales for which measurements have been made (USGS, 2008; Partin et al., 2013). The distributions of formation-scale TOC values assigned to shale volumes in our model (see supplementary online material section S2) are also congruent with the empirical distributions (grey, black and white horizontal bar in Fig. 5).

\section{Discussion}

Without compelling evidence for markedly different average sediment properties in the Precambrian compared to the Phanerozoic (Fig. 5), the notable concordance between empirical sediment abundance and $p \mathrm{O}_{2}$ histories shown in Fig. 1 becomes sensible in the context of total net organic carbon accumulation - i.e., burial in stable continental sediments which constitute the net sedimentary rock record, an idea first developed for Ronov's global Phanerozoic syntheses (Budyko et al., 1987; Berner and Canfield, 1989). Previous $p \mathrm{O}_{2}$ models included pyrite burial as a source of $\mathrm{O}_{2}$ because the reduction of seawater sulfate via microbial respiration transfers reducing power from organic carbon to pyrite (Berner and Canfield, 1989). Because pyrite burial is not a direct source of oxygen, we do not include it here; nevertheless, results are comparable when pyrite burial is included (supplementary online material section S3, Fig. S5).

To model sinks of $\mathrm{O}_{2}$, we empirically parameterize the oxidation of iron in oceanic crust (Lécuyer and 


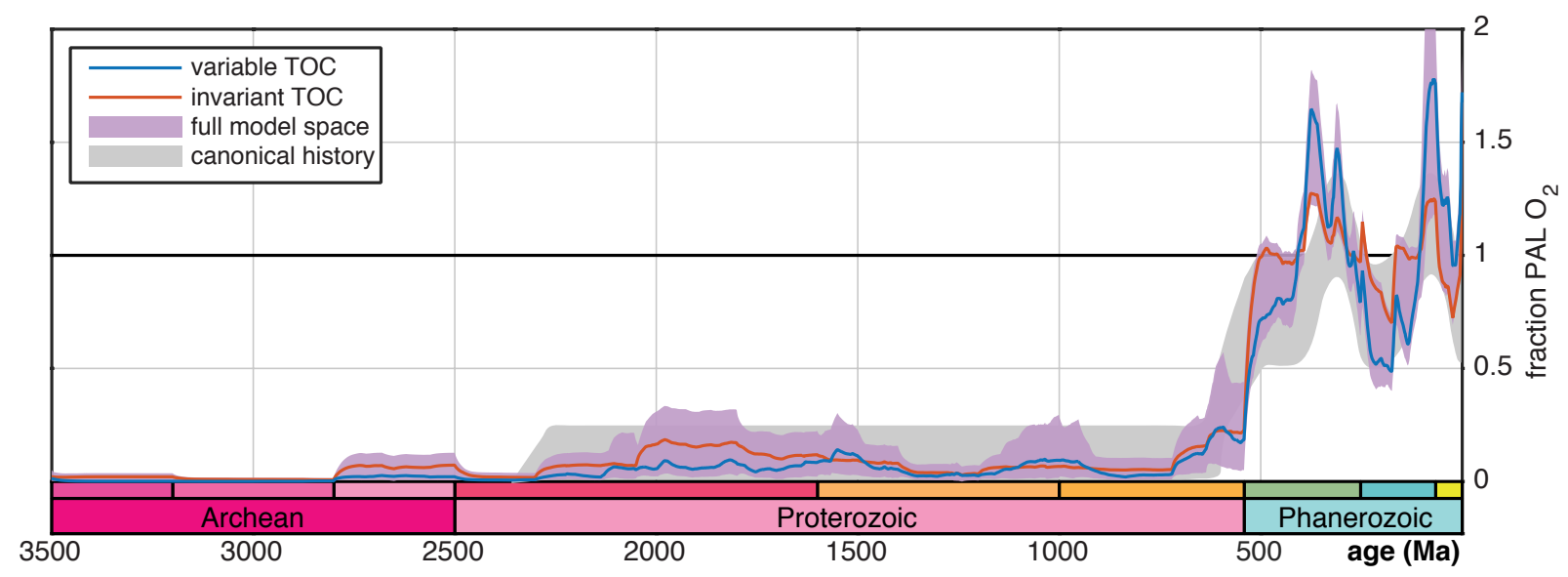

Figure 6: Following Equation 1 of the text, atmospheric $p \mathrm{O}_{2}$ is predicted. The 'variable TOC' model uses the blue curve in Fig. 4c as the $F_{\text {org }}$ term, whereas the 'invariant TOC' model uses the red curve. Any solution between these end-members is viable. The full model space (shaded region) also includes uncertainties in the end-member $F_{\text {org }}$ models estimated by 1000 randomizations of sediment properties used to define organic carbon flux (supplementary online material section S2). Displayed in grey is the independently derived canonical history of atmospheric oxygen (Lyons et al., 2014).

Ricard, 1999) and the oxidative weathering of sediments on land (Lasaga and Ohmoto, 2002). The numerical model for $p \mathrm{O}_{2}$ is:

$$
\frac{d M}{d t}=F_{\text {org }}-k_{1} M-k_{2} B_{\text {org }} \sqrt{M}
$$

where $M$ is the mass of $\mathrm{O}_{2}$ in the surface environment (in moles), $F_{\text {org }}$ is the net burial of organic carbon in continental settings (in moles/Myr), $B_{\text {org }}$ is total accumulated sedimentary organic carbon (in moles), $k_{1} M$ is the consumption of $\mathrm{O}_{2}$ via iron oxidation, and $k_{2} B_{\text {org }} \sqrt{M}$ is the oxidation of reduced phases (i.e., organic carbon and pyrite) in Earth's sedimentary shell (supplementary online material section S4).

Possible functions for $F_{\text {org }}$ include any linear combination of the burial histories in Fig. 4c, which in turn defines a family of solutions for the history of atmospheric oxygen (Fig. 6). In all model predictions, atmospheric oxygen is present only transiently in the Archean, which is suggestive of $\mathrm{O}_{2}$ 'whiffs' implied by certain proxy records (Lyons et al., 2014). The first permanent rise in $\mathrm{O}_{2}$ occurs at $\sim 2300 \mathrm{Ma}$. For the rest of the Proterozoic, $p \mathrm{O}_{2}$ remains low (ranging from $\sim 0.01$ to $0.30 \mathrm{PAL}$, with a mean value of $\sim 0.09 \mathrm{PAL}$ ). Atmospheric $p \mathrm{O}_{2}$ then begins to rise in the Neoproterozoic, but does not achieve modern-like values until the late Cambrian at 500 Ma under the 'invariant TOC' model, and not until the Early Devonian ( 400 Ma) under the 'variable TOC' forcing. After the second large rise in the early to middle Paleozoic, $p \mathrm{O}_{2}$ ranges between $\sim 0.5$ to $2 \mathrm{PAL}$, a dynamic range that is comparable to other $p \mathrm{O}_{2}$ models for the past 500 Myr (Berner and Canfield, 1989; Bergman et al., 2004).

Equation 1 is a simple forward model for atmospheric oxygen that encompasses continental organic carbon burial and aspects of oxidative weathering. More complex variations of the model could include, for example, more reducing volcanism in the Archean (Holland, 1984), the effects of a growing marine sulfate 
reservoir and pyrite deposition (Berner and Canfield, 1989), and feedbacks between $p \mathrm{O}_{2}$ and the TOC content of sediments (Hedges and Keil, 1995). However, our principal insight is not a specific model formulation, but is instead the empirical evidence that organic carbon accumulation on continental crust has evolved substantially across Earth history. Major inflection points in the record of net sediment storage coincide in timing and in relative magnitude with state changes in the history of $p \mathrm{O}_{2}$ and major transitions in the biosphere (Fig. 1). Model variants postulating that there has been no such change in continental sediment accumulation, and that the observed sedimentary record is dominated by the effects of post-depositional erosion, requires that the hypothetical missing sediments had properties that are different than all surviving sediments (supplementary online material section S5 and Figs. S6, S7), or that oxygen sinks were far higher in the Proterozoic, which lacks independent evidence (Derry, 2015; Keller and Schoene, 2012).

The suggestion that sources of $\mathrm{O}_{2}$ must have been weak to maintain low Proterozoic $p \mathrm{O}_{2}$ is not new, but in the absence of direct estimates for $F_{\text {org }}$ (Fig. 4c), this condition has previously been attributed to a variety of factors. Examples include a dominance of anoxygenic photosynthesis in the Proterozoic (Johnston et al., 2009), although biomarker tests of this hypothesis are inconclusive (French et al., 2015), as well as phosphorus limitation on biological productivity (Laakso and Schrag, 2014; Derry, 2015). The latter stands in contrast to isotope-based models of the Proterozoic carbon cycle. Although previous work has noted isotopic evidence for transient increases in fractional organic carbon burial near the end-Archean and endProterozoic boundaries (Knoll et al., 1986; Des Marais et al., 1992), background Proterozoic organic carbon burial fluxes have been interpreted as comparable to the Phanerozoic average (Krissansen-Totton et al., 2015) despite putatively low Proterozoic $p \mathrm{O}_{2}$ (Fig. 1). This potential inconsistency has to led to challenges against canonical models that invert carbon isotopic time series for organic carbon burial histories (Schrag et al., 2013).

A full treatment of the implications of our results for carbon isotopic records is beyond the scope of the present paper, but expectations for two end-member hypotheses can be articulated. The first is that low continental sediment accumulation in the Precambrian (Figs. 1 and 4) reflects overall lower exogenic carbon flux to the surface system, such that while isotopic determinations of fractional organic carbon burial in the Precambrian may be broadly correct, the implied absolute fluxes may be vastly different from those in the Phanerozoic. The second hypothesis stems from the fact that we demonstrate covariation between proxy records of atmospheric oxygen concentration and continental organic carbon storage (Fig. 1). The latter can diverge from the total carbon burial flux if the locus of that burial shifts from the stable continents to the tectonically less stable ocean floor, with implications dependent upon the long-term fate of buried carbon (see Hayes and Waldbauer (2006) and supplementary online material section S6). Determining which of these scenarios, if either, is correct depends upon identifying the ultimate cause for the increase in continental sediment storage (Fig. 1) and its potentially much broader implications for the Precambrian Earth system.

Regardless, it is apparent that the empirically determined record of net sediment accumulation on the continents contains considerable explanatory power for the history of atmospheric oxygen, even in the absence 
of a specific model for carbon burial (Fig. 1). The forward model presented here (Fig. 6), calibrated with sedimentary volumes (Fig. 4) and total organic carbon measurements (Fig. 5), makes several predictions that are congruent with previous notions about the trajectory of $p \mathrm{O}_{2}$ across geologic time: $\mathrm{O}_{2}$ concentration began a protracted rise during the end-Proterozoic (Sahoo et al., 2012), remained below modern levels until well into the Paleozoic (Bergman et al., 2004; Sperling et al., 2015), reached maxima during the Carboniferous and Cretaceous (Berner and Canfield, 1989; Bergman et al., 2004), and dropped to a Phanerozoic minimum at the end-Paleozoic/early-Mesozoic transition (Berner, 2005). The emerging idea that $p \mathrm{O}_{2}$ may have been near-modern levels following the GOE (Lyons et al., 2014) also has some amount of support, if we tenuously hypothesize that a small peak in Paleoproterozoic sediment area represents an initial Great Unconformitylike episode (Peters and Gaines, 2012) of continental sediment accumulation that was removed prior to the initiation of a second, Phanerozoic iteration of the same process (supplementary online material section S7, Fig. S9).

\section{Conclusions}

Given the overall dependence of net $\mathrm{O}_{2}$ production on the net burial of organic carbon in sedimentary deposits, it is not surprising that the empirical history of long-term, net continental sediment accumulation and its organic carbon content (Figs. 1,4) has some similarities to and bearing on the empirical history of atmospheric $p \mathrm{O}_{2}$ (Fig. 6). What is surprising, and as yet unexplained, is why the continents should undergo such a large step-wise transition in their capacity to act as long-term net sediment storage reservoirs. A potential mechanism includes changes in the average amount of continental crust that is flooded by shallow seas, possibly driven by changes in continental freeboard and the growth of the continental crust, neither of which is well known (Lee et al., 2016). A notable challenge for geoscience is identifying the specific causes of the abrupt transition in continental sediment accumulation that occurs at the start of the Phanerozoic.

Regardless of the ultimate mechanisms that drive changes in the ability of the continents to serve as long-term sediment storage reservoirs, recognizing that geodynamic factors, operating in conjunction with biological production of $\mathrm{O}_{2}$, have governed the timing and magnitude of major transitions in Earth's surface redox state must affect our understanding of the long-term evolution of life and environment. In this view, delays between the origin of eukaryotes and the appearance of metabolically demanding metazoan body plans during the Cambrian (Erwin et al., 2011) depended little on biological factors. Instead, animal diversification was determined largely by the timing of a state transition in the capacity of the continents to sequester photosynthetic organic carbon and, therefore, to serve as sources of $\mathrm{O}_{2}$. A corollary of this hypothesis is that returns to low Precambrian-like rates of continental sediment storage may be threats to complex animal life (Fig. 1). It is likely that just such a forcing, driven tectonically by the formation of Pangea (Hannisdal and Peters, 2011) and subsequent subaerial exposure of continental shelves, contributed to the severity of the end-Permian mass extinction (Knoll et al., 2007). Earth's ability to sequester sediments in tectonically stable continental settings is, therefore, a planetary process that is necessary for both the 
initial evolution of complex $\mathrm{O}_{2}$-metabolizing animal life and its long-term maintenance.

\section{Acknowledgments}

This work was funded by the University of Wisconsin - Madison Department of Geoscience, and the grants NSF EAR-1150082 and NSF ICER-1440312. Adam Maloof, Michael Foote, Seth Finnegan and Francis Macdonald provided comments on early drafts of this manuscript.

\section{References}

Bartley, J., Kah, L., 2004. Marine carbon reserovir, $\mathrm{C}_{\text {org }}-\mathrm{C}_{\text {carb }}$ coupling, and the evolution of the Proterozoic carbon cycle. Geology 32, 129-132.

Bergman, N.M., Lenton, T.M., Watson, A.J., 2004. COPSE: a new model of biogeochemical cycling over Phanerozoic time. American Journal of Science 304, 397-437.

Berner, R.A., 2005. The carbon and sulfur cycles and atmospheric oxygen from middle Permian to middle Triassic. Geochimica et Cosmochimica Acta 69, 3211-3217.

Berner, R.A., Canfield, D.E., 1989. A new model for atmospheric oxygen over Phanerozoic time. Am. J. Sci 289, 333-361.

Budyko, M.I., Ronov, A.B., Yanshin, A.L., 1987. History of the Earth's atmosphere.. volume 1. SpringerVerlag.

Chamberlin, T.C., 1899. An attempt to frame a working hypothesis of the cause of glacial periods on an atmospheric basis. The Journal of Geology 7, 545-584.

Derry, L.A., 2015. Causes and consequences of mid-Proterozoic anoxia. Geophysical Research Letters 42, $8538-8546$.

Des Marais, D., Strauss, H., Summons, R., Hayes, J., 1992. Carbon isotope evidence for the stepwise oxidation of the Proterozoic environment. Nature 359.

Erwin, D.H., Laflamme, M., Tweedt, S.M., Sperling, E.A., Pisani, D., Peterson, K.J., 2011. The Cambrian conundrum: early divergence and later ecological success in the early history of animals. Science 334, 1091-1097.

Farquhar, J., Bao, H., Thiemens, M., 2000. Atmospheric influence of Earth's earliest sulfur cycle. Science 289, $756-758$.

French, K., Rocher, D., Zumberge, J., Summons, R., 2015. Assessing the distribution of sedimentary C40 carotenoids through time. Geobiology 13, 139-151. 
Garrels, R.M., Mackenzie, F.T., 1969. Sedimentary rock types: relative proportions as a function of geological time. Science $163,570-571$.

Garrels, R.M., Mackenzie, F.T., 1971a. Evolution of sedimentary rocks. Norton, New York.

Garrels, R.M., Mackenzie, F.T., 1971b. Gregor's denudation of the continents. Nature 231, 382-383.

Gregor, B., 1970. Denudation of the continents. Nature 228, 273-275.

Gregor, C., 1968. Rate of denudation in post-algonkian time. Proceedings of the Koninklklijke Nederlandse Akademie van Wetenschappen Series B-Physical Sciences 71, 22.

Halverson, G., Hoffman, P., Maloof, A., Schrag, D., Rice, A.H.N., Bowring, S., Dudas, F., 2005. Toward a Neoproterozoic composite carbon-isotope record. Geological Society of America Bulletin 117, 1181-1207.

Hannisdal, B., Peters, S.E., 2011. Phanerozoic Earth system evolution and marine biodiversity. Science 334, $1121-1124$.

Hayes, J.M., Waldbauer, J.R., 2006. The carbon cycle and associated redox processes through time. Philosophical Transactions of the Royal Society B: Biological Sciences 361, 931-950.

Hedges, J.I., Keil, R.G., 1995. Sedimentary organic matter preservation: An assessment and speculative synthesis. Marine Chemistry 49, 81-115.

Holland, H.D., 1984. The chemical evolution of the atmosphere and oceans. Princeton University Press.

Holland, H.D., 1999. When did the Earth's atmosphere become oxic? A reply. Geochemical News 100, $20-22$.

Johnston, D.T., Wolfe-Simon, F., Pearson, A., Knoll, A.H., 2009. Anoxygenic photosynthesis modulated Proterozoic oxygen and sustained Earth's middle age. Proceedings of the National Academy of Sciences 106, 16925-16929.

Keeling, R.F., Piper, S.C., 1996. Global and hemispheric $\mathrm{CO}_{2}$ sinks deduced from changes in atmospheric $\mathrm{O}_{2}$ concentration. Nature 381, 16.

Kelemen, P.B., Manning, C.E., 2015. Reevaluating carbon fluxes in subduction zones, what goes down, mostly comes up. Proceedings of the National Academy of Sciences 112, E3997-E4006.

Keller, C.B., Schoene, B., 2012. Statistical geochemistry reveals disruption in secular lithospheric evolution about 2.5 Gyr ago. Nature 485, 490-493.

Kirschvink, J.L., Kopp, R.E., 2008. Palaeoproterozoic ice houses and the evolution of oxygen-mediating enzymes: the case for a late origin of photosystem II. Philosophical Transactions of the Royal Society of London B: Biological Sciences 363, 2755-2765. doi:10.1098/rstb.2008.0024. 
Knoll, A., Hayes, J., Kaufman, A., Swett, K., Lambert, I., 1986. Secular variation in carbon isotope ratios from Upper Proterozoic successions of Svalbard and east Greenland. Nature 321, 832-837.

Knoll, A.H., Bambach, R.K., Payne, J.L., Pruss, S., Fischer, W.W., 2007. Paleophysiology and end-Permian mass extinction. Earth and Planetary Science Letters 256, 295-313.

Krissansen-Totton, J., Buick, R., Catling, D.C., 2015. A statistical analysis of the carbon isotope record from the Archean to Phanerozoic and implications for the rise of oxygen. American Journal of Science $315,275-316$.

Laakso, T.A., Schrag, D.P., 2014. Regulation of atmospheric oxygen during the Proterozoic. Earth and Planetary Science Letters 388, 81-91.

Lasaga, A.C., Ohmoto, H., 2002. The oxygen geochemical cycle: dynamics and stability. Geochimica et Cosmochimica Acta 66, 361-381.

Lécuyer, C., Ricard, Y., 1999. Long-term fluxes and budget of ferric iron: implication for the redox states of the Earth's mantle and atmosphere. Earth and Planetary Science Letters 165, 197-211.

Lee, C.T.A., Yeung, L.Y., McKenzie, N.R., Yokoyama, Y., Ozaki, K., Lenardic, A., 2016. Two-step rise of atmospheric oxygen linked to the growth of continents. Nature Geoscience 9, 417-424.

Lyons, T.W., Reinhard, C.T., Planavsky, N.J., 2014. The rise of oxygen in Earth's early ocean and atmosphere. Nature 506, 307-315.

Mackenzie, F., Pigott, J., 1981. Tectonic controls of Phanerozoic sedimentary rock cycling. J. Geol. Soc. London 138, 183-196.

Meyers, S.R., Peters, S.E., 2011. A 56 million year rhythm in North American sedimentation during the Phanerozoic. Earth and Planetary Science Letters 303, 174-180.

Partin, C., Bekker, A., Planavsky, N., Scott, C., Gill, B., Li, C., Podkovyrov, V., Maslov, A., Konhauser, K., Lalonde, S., et al., 2013. Large-scale fluctuations in Precambrian atmospheric and oceanic oxygen levels from the record of U in shales. Earth and Planetary Science Letters 369, 284-293.

Peters, S.E., 2006. Macrostratigraphy of North America. The Journal of Geology 114, 391-412.

Peters, S.E., Gaines, R.R., 2012. Formation of the 'Great Unconformity' as a trigger for the Cambrian explosion. Nature 484, 363-366.

Reinhard, C.T., Planavsky, N.J., Robbins, L.J., Partin, C.A., Gill, B.C., Lalonde, S.V., Bekker, A., Konhauser, K.O., Lyons, T.W., 2013. Proterozoic ocean redox and biogeochemical stasis. Proceedings of the National Academy of Sciences 110, 5357-5362. 
Ronov, A., 1982. The Earth's sedimentary shell (quantitative patterns of its structure, compositions, and evolution) the 20th VI Vernadskiy Lecture, March 12, 1978. International Geology Review 24, $1313-1363$.

Ronov, A., Khain, V., Balukhovsky, A., Seslavinsky, K., 1980. Quantitative analysis of Phanerozoic sedimentation. Sedimentary Geology 25, 311-325.

Rowley, D.B., 2002. Rate of plate creation and destruction: 180 Ma to present. Geological Society of America Bulletin 114, 927-933.

Sahoo, S.K., Planavsky, N.J., Kendall, B., Wang, X., Shi, X., Scott, C., Anbar, A.D., Lyons, T.W., Jiang, G., 2012. Ocean oxygenation in the wake of the Marinoan glaciation. Nature 489, 546-549.

Schrag, D.P., Higgins, J.A., Macdonald, F.A., Johnston, D.T., 2013. Authigenic carbonate and the history of the global carbon cycle. Science 339, 540-543.

Scott, C., Lyons, T.W., Bekker, A., Shen, Y., Poulton, S.W., Chu, X., Anbar, A.D., 2008. Tracing the stepwise oxygenation of the Proterozoic ocean. Nature 452, 456-459.

Sperling, E.A., Wolock, C.J., Morgan, A.S., Gill, B.C., Kunzmann, M., Halverson, G.P., Macdonald, F.A., Knoll, A.H., Johnston, D.T., 2015. Statistical analysis of iron geochemical data suggests limited late Proterozoic oxygenation. Nature 523, 451-454.

USGS, 2008. Geochemistry of rock samples from the National Geochemical Database. Technical Report. U.S. Geological Survey.

Wold, C.N., Hay, W.W., 1990. Estimating ancient sediment fluxes. American Journal of Science 290, 1069-1089. 